\title{
UNIVERSITY STUDENTS' VIEWS OF THE ROLE OF MATHEMATICS IN THEIR FUTURE
}

\author{
Leigh N. Wood*, Glyn Mather, Peter Petocz, Macquarie University, Sydney, Australia \\ Anna Reid, University of Sydney, Australia \\ Johann Engelbrecht, Ansie Harding, University of Pretoria, South Africa \\ Ken Houston, University of Ulster, United Kingdom \\ Geoff H. Smith, University of Technology, Sydney, Australia \\ Gillian Perrett, Universiti Brunei Darussalam
}

\begin{abstract}
We report on an international study about mathematics students' ideas of how they will use mathematics in their future study and careers. This builds on our previous research into students' conceptions of mathematics. In this paper we use data from two groups of students studying mathematics: those who participated in an in-depth interview and those who completed an open-ended questionnaire. Using a content analysis, we found that their responses could be grouped into four categories: don't know; procedural skills; conceptual skills; and professional skills. Although some students held clear ideas about the role of mathematics, many were not able to articulate how it would be used in their future. This has implications for their approach to learning and our approach to teaching.
\end{abstract}

KEYWORDS: conceptions of mathematics, mathematics in careers, mathematics in tertiary study, teaching and learning

\section{INTRODUCTION}

For many of us in the mathematics community, it seems self-evident that mathematics is a discipline that can underpin one's view of the world. Some of our students agree: one third-year student wrote "it's a very powerful subject - mathematics - to get more advanced life for human beings." A working life can be built solely around mathematics on this basis. For other students there seems to be complete incomprehension about what mathematics is and how it could be applied beyond the context of a university subject. Many fall in a middle ground, where they see mathematics as a handy skill that can be quite useful for particular purposes.

We are engaged in a long-term international study that focuses on students' notions of mathematics, learning mathematics and the role of mathematics in their profession. In this paper we investigate students' ideas about their anticipated future use of mathematics - in their further studies and their future professional life. We present results from two groups of students studying mathematics: a group who participated in an in-depth interview early in our study at one university (22 students) and a much larger group from five universities in five countries who completed an open-ended questionnaire $(1,182$ students). Participants included those who were aiming to become professional mathematical scientists, others who were studying mathematics as a core part of their curriculum within a separate discipline (such as engineering or finance), and a group of students who had chosen to study some mathematics as part of a seemingly unrelated degree course, such as international studies.

\footnotetext{
${ }^{*}$ Author for correspondence
} 
Our interest in this area arose in part from changes in the tertiary sector in terms of the massification of universities, that is, from an ivory tower to institutions open to all (Crebert et al., 2004) and which have an emphasis on training people for careers. A particular change in Australia and elsewhere is the increase in fee-paying international students, who tend to be focused on future careers rather than learning per se. There has been wide discussion of the possible implications for teaching mathematics as a result of this new emphasis on careers. In a discussion of trends in tertiary mathematics education, Selden (2005) suggests that, "the larger academic community advocates ... that secondary school graduates be better prepared mathematically for both university and the workplace by taking more, and better, mathematics courses." (p. 137; our emphasis).

In addition, there has been rapid technological change in the mode of delivery of mathematics and the teaching of mathematics, partly to mirror changes within work environments. Many studies have addressed the consequences for teaching of this increased use of computer software: Selden (2005) notes that "while many of the uses of the computer are essentially computational, enabling students to investigate problems involving 'messy' real world data, others are meant to facilitate both procedural and conceptual learning of mathematical topics" (p. 133).

Learning mathematics will be influenced by such changes in the teaching context of mathematics, as well as by students' own conceptions of mathematics, and this in turn will affect their views about the role of mathematics in their future studies and career. The great majority of students taking mathematics subjects at university have also studied mathematics at high school, and therefore come to university with an existing body of beliefs and conceptions of mathematics. In fact, an Australian study of engineering students studying mathematics suggested that facility with mathematics and physics at high school played a major part in their choice of university course (Wood et al., 2003). Macbean (2004, p. 553) suggests that "many factors affect the quality of student learning. The students' conceptions of and approaches to learning, their prior experiences, perceptions and understanding of their subject, and the teaching and learning context can all influence the learning outcomes achieved."

Student conceptions of mathematics as a subject and its utility in our students' future is our focus in this paper, as this relationship can have profound effects on their learning. Our previous research into conceptions of mathematics (Reid et al., 2003; Petocz et al., 2007), utilising phenomenographic analyses (Marton \& Booth, 1997), has revealed them to be hierarchical - three levels of conceptions were identified, with the broadest (mathematics is an approach to life and a way of thinking) incorporating an intermediate conception (mathematics is about building and using models, both specific models of aspects of reality and abstract models of logical structures), and this in turn incorporated the narrowest view (mathematics as a toolbox of individual components and procedures, maybe even only numerical calculations). Research by other investigators has followed a similar path, with some correspondence with the classifications we derived. For example, Prosser and Trigwell (1999) found that students have a spectrum of conceptions between fragmented and cohesive. With a fragmented conception students were likely to use a surface approach to their study, while those with a cohesive conception were more likely to use a deep approach, and this connection has been established in many subject areas including mathematics. 
There have been other studies specifically on student conceptions of mathematics. An earlier piece of research in this area is that by Crawford et al. (1994, 1998), who undertook a multi-stage study of Australian tertiary students' conceptions of mathematics and how mathematics is learned. Their study was carried out in large first-year mathematics classes, comprised for the most part of students who were required to take a mathematics class as part of a major study in some other area. They explored the relationship between the students' own perceptions of the discipline and their learning using a combination of qualitative and quantitative methods. The results suggested a correlation between students' conceptions of the subject and their approach to learning; that is, at the end of their first year, university students with a surface approach to learning did not do as well as students who had a deeper approach to learning.

Houston (1997) also focused on student views and considered three ways in which students experience mathematics in the context of mathematical modelling, which will in turn influence their conceptions of mathematics. A student learns methods, or tools; the tools are used to understand models of the universe created by others; finally, this understanding of methods and models enables the student to engage in the creative activity of building models, and modelling becomes a way of life.

These conceptions of mathematics are foundations for the views students hold of the role mathematics will play in their future. Some researchers have investigated students' views about various aspects of their future, though most of these studies have focused on generic conceptions, particularly of high school students. Dick and Rallis (1991), in a study in the US, looked at the reasons behind high school students' career choices. They suggested that "a career's perceived value is determined by intrinsic factors such as intellectual interest as well as extrinsic factors such as salary expectation and the cost and length of future training" (p. 283). The expectations of others, such as parents and teachers, can also influence career choice.

Husman and Lens's approach (1999) to a similar question was to use the concept of future time perspective (FTP), defined as "the degree to which and the way in which the chronological future is integrated into the present life-space of an individual through motivational goal-setting processes" (p. 114). Individuals vary in their perspectives, from short to long term, and therefore so does the time span for which they make plans, with consequences for their motivation towards learning.

A large study in Europe (Sweden, Poland, Norway and Germany) called the "Journeymen Project" (Dahlgren et al., 2007; Abrandt Dahlgren et al., 2006) tracked students' transition from university to work. The results highlighted national differences in disciplines including psychology and political science, which may also be reflected in a variety of university entry requirements for mathematics programs. The researchers were particularly interested in the types of learning experiences associated with different disciplines and how these correlated with workplace experiences. For example, psychology students in Sweden were taught using a problem-based learning approach that reflected their likely work situations. They reported fewer transition problems than the engineering students, who were taught in a more traditional way.

There is also a growing body of literature on the development of graduate skills and the qualities of successful graduates, for example, work by Scott and Yates (2002) and Rochester, Kilstoff and Scott (2005). From investigations focusing on particular fields of study, these authors have developed a 'Graduate Capability Framework'. Their research 
highlights that it is when things go wrong, when an unexpected or troubling problem emerges, that professional capability is most tested, not when things are running smoothly or routinely. It is at times like these that an individual must use the combination of a well-developed emotional stance and an astute way of thinking in order to understand ('read') the situation and, from this, to figure out ('match') a suitable strategy for addressing it, a strategy which brings together and delivers the generic and jobspecific skills and knowledge most appropriate to the situation.

A complementary approach is to consider those graduates who fail to find professional employment. In a small study of unemployed graduates in the UK (Knight \& Yorke, 2003), participants referred to the 'degree-work mismatch', feeling that they had learned to execute a limited number of academic procedures but remained deficient in areas such as self-presentation, self-motivation and communication. Many considered that they would need further qualifications before getting an appropriate job, and suggested that lecturers could include discussion about employability and careers as part of the curriculum from first year.

However, there is very little research on whether career-oriented skills are being developed within the teaching of mathematics. The links have not been made between mathematics students and the proficiencies they require to succeed in the workforce, and in particular how these students view their future. Some of the Australian authors in our team have been investigating the learning and teaching of mathematics for those who will specialise in the discipline (Wood \& Kaczynski, 2005; Petocz \& Reid, 2006; Wood \& Reid, 2006); there is, however, a lack of information about the mathematical skills and perceptions of those in other disciplines who will nonetheless need to use mathematics in their working lives.

Our overall study seeks to address these issues. The first stage consisted of interviews carried out at an Australian university with students intending to be mathematicians, where the focus was on these students' conceptions of mathematics and approaches to learning mathematics (reported in Reid et al., 2003, 2005). From this initial phase, a questionnaire with three open-ended questions was developed and administered to almost 1200 students from a wide range of backgrounds and disciplines at five universities in five countries. The first question dealt specifically with students' conceptions of mathematics and the results have been described in Petocz et al. (2007); that paper also includes an analysis of those variables which emerged as significant (such as university and year of program). The present paper is a discussion of the findings from the other two questions - What part do you think mathematics will play in your future studies? ... in your future career? - dealing with students ideas of the future role of mathematics in their studies and their careers. We have continued our investigations by developing a closed-question survey utilising the earlier results: this has been trialled on a larger group of students at the same universities, and will be further expanded to other universities.

\section{RESEARCH DESIGN}

The study was inspired by an interest about students' ideas on mathematics and its use in their future careers as part of an initiative to enhance the curriculum for mathematics undergraduates. Initially, 22 students studying undergraduate mathematics at one university were interviewed one-on-one about their ideas of mathematics, learning mathematics and what it would be like to work as a mathematician. The students were all 
undertaking degrees in mathematical sciences at the University of Technology, Sydney (UTS) majoring in statistics, operations research or mathematics and finance.

The results from this investigation were so intriguing that we widened the study to include five countries and students from other disciplines. The cross-country component was partly fortuitous, as some of us had met at international conferences over the years. It was also advantageous as it gave a wider cultural spread, that is, a cross-section of English-speaking students from Australia, Canada, Northern Ireland and South Africa; a French-speaking cohort from Canada; an Afrikaans-speaking cohort from South Africa; Malaysian speakers from Brunei; and people from a variety of non-English speaking backgrounds at the Australian and Canadian universities (both international students and local residents). The disciplines included some requiring mathematics as a core subject (such as engineering, finance and business) and others where it was regarded more as an elective (international studies, for example). The students also came from different years of undergraduate study. The effects of some of these variables on the conceptions of mathematics have been discussed in Petocz et al. (2007).

The number of students available from these five universities led to the adoption of a questionnaire mode of investigation rather than interviews as a matter of pragmatism. However, since the aim was to elicit the range of opinion rather than imposing a predetermined set of ideas, three open-ended questions were formulated:

Question 1. What is mathematics?

Question 2. What part do you think mathematics will play in your future studies? Question 3. What part do you think mathematics will play in your future career?

To analyse the data from the first question, we used an approach based on knowledge of the previously-developed phenomenographic categories of conceptions of mathematics (reported in Reid et al., 2003). Since questions equivalent to numbers 2 and 3 did not form an explicit part of the initial interview study, we do not have phenomenographic categories as a starting point, though we do have access to some relevant comments from the students we first interviewed. While it was possible to classify the responses to the first question in the survey in a hierarchical fashion, a common outcome from phenomenographic analyses, this was not viable for responses concerning the role of mathematics in future studies or in a future career. In fact, some confusion arose when we tried to construct a hierarchical classification. Do students who can name particular components of mathematics that will be used in their future careers show a deeper or narrower understanding of the potential job than students who respond that they will use a fair amount of mathematics because they aim to be actuaries?

Our approach to the analysis of data concerning students' ideas about the future use of mathematics in their studies and their careers was to utilise a content analysis (Weber, 1990). The unit of analysis was the sentences or coherent groups of sentences in the interview transcripts and the individual responses on the questionnaire. We start by drawing out the relevant information from the original interview study, establishing the themes of our categorisation. Then we report on responses to questions 2 and 3 in the survey, students' ideas about the role of mathematics in their future study and career. The reliability of analysis of the questionnaire responses was achieved by having four of the authors (LNW, JE, AH, GHS) classify responses independently: differences were resolved by discussion with the team. We found that the interview responses were readily grouped into one category per response. 


\section{RESULTS}

\section{Role of Mathematics in Future Career: Interviews}

This section deals with responses from our earlier interviews, specifically responses dealing with students' ideas of what it will be like to work as a mathematician and what they believe they will take with them into their future employment. Though they were not asked specifically about the role of mathematics in their future, many of the interviews did include some responses that we were able to identify as relating to their careers. A revealing result was that many students literally had no idea of what role mathematics would play in their future careers even though they were studying a mathematics degree.

Our content analysis of these comments could be grouped into four categories: no idea; procedural skills (the study of mathematics will furnish them with procedures to use in their professions); conceptual skills (mathematical problem-solving and analytical skills, and approaches based on mathematical logic); and professional skills (generic skills or combinations of skills that will play a fundamental role in the context of professional work). We have utilised these categories in assessing the development of graduate skills in the context of undergraduate business education, where they can be formulated as 'knowing how' (procedural), 'knowing that' (conceptual) and 'knowing for' (professional) (EDGGS, 2010). These categories allow us to describe the range of ideas that students had, and form a basis for checking the validity of the later (and much briefer) questionnaire responses. A short description of each category, with illustrative quotes from the students, is presented here (the students' names in the quotes are pseudonyms).

No idea. Many students had little idea of what they might be doing as a mathematician. It was sometimes even difficult for them to see themselves as a mathematician or know what they could offer an employer with their mathematical skills.

Candy ( $3^{\text {rd }}$ year): I can't really imagine what it will be like to work as a mathematician, or be recognised as a mathematician until I graduate ... It's not like an accountant, lawyer, like that's just straight away "Oh I need one of those" but like with a mathematician, "What can I do with a mathematician, what do I need one for?" you know. So I'm not exactly sure, because right now that's what I think as well ...

Procedural skills. Some students had the idea that mathematics could be used as a toolbox of procedures to select from when needed in their further career. This seemed to describe a point of view about the role of mathematics, rather than the depth or complexity of the mathematics itself. The tools may be simple or very intricate but they remain tools, and only certain isolated skills or techniques are regarded as relevant.

Richard (Honours): It's like a toolbox, you are getting a lot more tools and if you are a carpenter or something, before ... you just had a screwdriver, where you come back and now you have a screwdriver, a Phillips head, you've got pliers to do different things, you've got saws to shorten things ... you've got a lot more tools there to play with, so ... when you get into the workplace, you are much more of an attractive sort of employee to have, yeah.

Vitali ( $2^{\text {nd }}$ year): So mathematics is very simple tool if you know how to use it, and I hope I will use it efficiently and effectively in the finance world. 
Conceptual skills. Here the perception was that studying mathematics develops conceptual skills such as the logical thinking associated with proofs and mathematical problem-solving skills useful for deepening understanding in other disciplines.

Brad ( $2^{\text {nd }}$ year): I think it's one of the fundamental things, because mathematics is all based on proof. We, somebody, notices something happens in this particular case and then they sit down and establish whether it will happen in every single case, and all those proofs are based on logic.

Monique ( $3^{\text {rd }}$ year): After uni I probably have more skills in maths, like not just calculating and computing, but analysing problems, yeah, analysing and solving problems, because you know how employers, right, these days, they look for problem solving skills, problem solving, analytical.

Note that we are referring here to mathematical problem-solving skills rather than generic ones which would be better viewed as part of professional skills - Petocz and Reid (2006) discuss the range of conceptions of problem solving amongst recent mathematics graduates.

Professional skills. Some students perceived mathematics as playing an overwhelming role in their future career, but did not point to any specific role, referring rather to the generic benefit of studying mathematics, including skills such as high-level numeracy, communication in mathematical terms, and the ability to make sense of areas that are commonly presented using a mathematical approach.

Dave ( $3^{\text {rd }}$ year): I guess statistical consulting is something that interests me and it seems for that the skills you need are relatively narrow. I guess first and foremost you need the communication skills to, you know, figure out what is going on and relate it to your, whoever's employing you, your customer.

Julia (Honours): Well maths is the backbone of the financial world and how the finance world moves. ... the way they plan how to manage risk, the way how they sit down and analyse data, it's all connected with maths. Every financial book you open is full of maths. Very, very directly connected, you'd have to skim your way and wave your hands around a bit if you wanted to ignore the maths.

\section{Role of Mathematics in Future Studies: Questionnaire}

In this section we report on the $(n=1182)$ questionnaire results across the five universities specifically concerning the question What part do you think mathematics will play in your future studies? As discussed earlier in regard to the interviews, the responses to the role of mathematics in future studies seemed to be naturally classifiable into a horizontal categorisation. The categories revealed in the interrogation of the interview results were used as a guide for the analysis of the responses to the two questions from the survey.

There were students who simply did not know how they were going to use mathematics in their future studies or even, perhaps, what program they would be studying. Responses of students who showed some knowledge of how they were going to use mathematics were classified into those who referred to specific skills - either procedural skills or conceptual skills - and those who referred to professional skills. Because these data are derived from the questionnaire, it was possible to quantify the responses for each category (as number and percentage) in a way that could not be done for the interview data set. 
Some students gave short answers that did not provide enough information to be categorised. These responses have been coded for later analysis. These are students who said none $(40,3.4 \%)$, a small part $(36,3.0 \%)$ or a large part $(156,13.2 \%)$, a total of $19.6 \%$. Some of these responses suggest that students are aware that mathematics is required, but the responses were so brief that we could not fit them into the categories mentioned above. There were also a number that were either blank or unable to be deciphered $(74,6.3 \%)$.

Don't know (7.0\%). This category includes students who stated that they did not know what part mathematics would play $(39,3.3 \%)$ and those who simply said that mathematics was a structural necessity in their degree, such as, I must pass mathematics to get my degree (44, 3.7\%).

Procedural skills $(327,27.7 \%)$. As in the case of the interview responses, students who held this view had the idea that mathematics will be used as a toolbox of procedures to select from as needed in their further studies. Note again that this represents a reference to the role of mathematics, rather than its depth or complexity. The tools may be simple or very intricate but they remain tools. In this view, only isolated skills or techniques are regarded as relevant.

Help to calculate values such as heat loss in buildings and thickness of materials to be used.

At the moment I find that stochastics and statistics to be my most immediate and usable tools.

Conceptual skills $(82,6.9 \%)$. As with the interviews, here the perception is that studying mathematics develops conceptual mathematical skills, such as logical thinking and mathematical problem-solving skills, which are useful for deepening understanding in other disciplines.

It will help me to think logically and analytically. It will help me to think in different ways to people in business and engineering.

The principles of reasoning will always be relevant but the specific work done will be forgotten.

Professional skills $(384,32.5 \%)$. Again, mathematics in this conception is seen as playing a substantial role in future studies but no specific role is given. Rather, reference is made to generic ideas such as high-level numeracy, mathematical communication and understanding of mathematically-based areas. Students may hold this view because they are mathematics majors or contemplating a higher degree in mathematics, or simply believe that mathematics is an integral part of their studies.

I believe any postgraduate studies taken by me will be mathematically based. This is my main interest. I am interested in all streams of mathematics and want to increase my knowledge beyond the scope of my course.

Mathematics is integrated in all areas of my chosen course. I will be using mathematics throughout my further studies.

Included under this heading were responses that referred to mathematics as a foundation for further study (in mathematics or in other fields) without specific detail being given. 
The purpose of studying mathematics is to provide underlying principles in an area or discipline.

It provides a vital foundation for describing and characterising physical systems.

It has provided some very strong building blocks which allow me to investigate further topics of interest to me.

Also placed in this category were responses - around 10 percent $(120,10.2 \%)$ - where students asserted that they need to study mathematics because it is necessary for their career but gave only bald statements. They said that they will study a lot of mathematics because they are going to be, say, an actuary or an engineer; for example, Mathematics is essential for the career I want to follow.

\section{Role of Mathematics in Future Career: Questionnaire}

In this section we report on the results $(n=1182)$ of the survey question What part do you think mathematics will play in your future career? Once again, some students gave very brief answers, such as none $(27,2.3 \%)$, a small part $(48,4.1 \%)$ or a large part $(99$, $8.4 \%$ ), amounting to a total of $14.7 \%$. These responses have been coded but not included in the categorisation below. Others expressed the idea that very little mathematics will be used because it has been (or soon will be) superseded by technology: the machines will do the mathematics for you. These responses and the missing and undecipherable ones $(112,9.5 \%)$ have also been omitted from the categories described below.

Detailed re-reading of the whole body of material showed that the classification revealed by the responses on future studies was found to be equally suitable for the classification of responses about the perceived role of mathematics in the students' future professions. The categories are again illustrated by means of student quotes.

Don't know (55, 4.7\%). It was noticeable that some students felt uncertain about their future use of mathematics, and one even responded: Am I a fortune teller?

Procedural skills $(347,29.4 \%)$. This is the view of mathematics as a toolbox - students believe that mathematics will be used as a set of procedures to choose from as necessary in their future professions, and only certain isolated skills or techniques are relevant.

Mathematics will provide a way to find values and prices of various financial instruments.

I would like to be a data analyst, so statistics will help me perform the analysis.

Conceptual skills $(69,5.8 \%)$. Here the perception is that doing mathematics develops logical thinking and mathematical problem-solving skills. Mathematics can consequently be useful for deepening understanding in various areas or disciplines.

Studying mathematics has refined my problem-solving skills and analytical skills. It has helped develop my intuition in dealing with numerical and other problems.

It will allow me to make better judgements based on a sound knowledge of various types and forms of data.

Professional skills $(425,36.0 \%)$. With these responses students see mathematics as an integral part of their future career and they refer to various generic aspects of their 
mathematical studies. They may envisage the profession of mathematician, or they may believe mathematics to be an integral part of their future professional life.

Mathematics will play a huge part of my future career, as I hope to go into research or teaching.

It forms the basis of everything I will do for the rest of my life. My entire career will be based on mathematics.

Mathematics is also perceived here to be generally useful in a wide range of careers, or to be attractive to employers. Students expect to have generic skills such as high-level numeracy and mathematical communication that can be used in various contexts or to underpin a variety of disciplines.

It will increase my chances of getting a good job.

It will play a major role in my professional career and it is essential in most, if not all, professional jobs. Therefore it is essential to have.

Many of these students $(243,20.6 \%)$ stated that they needed mathematics for their career but with no details, such as, As an Actuary I think it is obvious that it will be essential.

\section{Results summary}

The group of students surveyed had many different views about mathematics and the part it will play in their future studies and career. We have been able to categorise these views into a small number of qualitatively different areas. The categories were essentially the same for the interview and the questionnaire, though we were only able to quantify results for the questionnaire (see Table 1).

TABLE 1

Student views of the future role of mathematics

\begin{tabular}{lcc}
\hline Questionnaire & Studies & Career \\
\hline Don't know & $83(7.0 \%)$ & $55(4.7 \%)$ \\
Procedural skills & $327(27.7 \%)$ & $347(29.4 \%)$ \\
Conceptual skills & $82(6.9 \%)$ & $69(5.8 \%)$ \\
Professional skills & $384(32.5 \%)$ & $425(36.0 \%)$ \\
Other and missing & $306(25.9 \%)$ & $286(24.2 \%)$ \\
\hline
\end{tabular}

In the questionnaire, many students gave the same or similar response to both the role of mathematics in future studies and future career, since they equally depend on the clarity of a student's view of their future. This is one of the reasons the same categorisation could be used for both dimensions. Students showed a variety of ways of anticipating the use of mathematics in their future studies and career. Many saw mathematics as a collection of tools for their future use, or a foundation set of conceptual skills for their future studies and the workplace, while some of them focused on the generic, professional skills that they anticipated applying in their career and even the remainder of their studies. 
Quantitatively, in each case we were able to classify around three-quarters of the responses, with the remaining quarter either missing or too brief for categorisation. In the career responses, a small but noticeable number of students (around 4\%) stated that computers would be doing their mathematical work for them, which could almost have been interpreted as a computational idea of mathematics and classified in the procedural conception. This is, however, a view that is important to address in teaching strategies as it resonates with research by Kent and Noss (2003) about the use of mathematics and computers in the engineering workplace.

\section{IMPLICATIONS FOR TEACHING AND LEARNING}

These results give us an idea of the views of students in our classes concerning their future use of mathematics. The challenge for us as educators is firstly to acknowledge that students hold widely differing ideas about what mathematics is and how they believe they will use it in the future. For some students, the results may be a reflection of uncertainty towards their future in general, which is difficult to address within a mathematics subject. For those who are planning a particular career, however, it is necessary to make the links between what is studied at university and what is involved in being a professional. The ideas revealed in our study are a reflection of students' experience and conceptions at that point in time and are therefore relevant to the way in which we, as professional mathematicians, try to mould and influence our students' attitudes to mathematics in their future studies and work.

It could be argued that the evidence presented on students' ideas about their future use of mathematics is limited by the nature of the way the data were collected - in the first instance, quotes from a small number of interviews investigating students' conceptions of mathematics, in the second case, written responses to three questions, many of which were missing, or gave no useful information on the question. It is true that the data could be improved. A larger number of interviews, focusing specifically on the question of future use of mathematics and carried out at a number of difference universities would undoubtedly yield more information. The questionnaire responses could certainly be improved, but students did have the opportunity (time and space) to write as much as they wanted, and some of them wrote several lines of response. The strength of the interviews lies in the opportunity to investigate students' ideas in detail, while the strength of the questionnaire is the large number of respondents from diverse locations and backgrounds. Previous investigations using this methodology have revealed useful findings about students' ideas (Loughland et al., 2002) despite numbers of missing or unclassifiable responses.

The possession of simplistic conceptions of mathematics has implications for learning: they can be an obstacle to understanding the mathematics that students are presented with as well as presenting difficulties for them when moving on to more sophisticated areas of mathematics. As suggested by Selden (2005, p. 140), "often people regard as 'easy' or 'natural' what they have already mastered, having forgotten their own sometimes tortuous path to expertise; this seems especially true of mathematical concepts." Relatively few responses in the questionnaire showed a "conceptual skills" notion of the use of mathematics (studies: 6.9\%; career; 5.8\%) as compared with the "procedural" or "professional" skills ideas. If we wish our students to reap the full benefits of mathematics, we need to advance the development of higher-order skills 
alongside an understanding of how these skills can be applied. Petocz and Reid (2006) propose that development of stronger links between learning mathematics and its use in their professional lives can bring students to, "view mathematics as a way of understanding the world, and hence apply the notion of problem solving to their personal as well as professional lives ..." (p. 8).

Equally, lack of clear ideas about the role of mathematics can affect interpretation of meaning and can have significant impacts on the motivation to learn. For instance, a number of students (4\%) held the view that in their career they would be able to rely on computers to do the work: Not very big. Computer programs will do all the work and applications for you. Maybe just the analysis of your answers. There has also been only limited discussion in the literature of what implications the changes in technology mean for those who are going to be using mathematics in their future work. For instance, many mathematics academics have discussed teaching using technological aids (Wood, 2004) such as graphics calculators or computer algebra systems, noting that part of the rationale for their introduction is that employers require their mastery. Clearly, some students are not getting the point that one needs to understand the underlying principles behind the software and equipment they are being taught to use.

Houston and McCartney (2007) describe a teaching innovation which is intended to show engineering students that their mathematics course and the technology it incorporates is indeed useful and not just something that must be endured and passed. The innovation involves the use of inexpensive, hand-held technology - graphing calculators and data-loggers - to take measurements during experiments and to analyse the data so as to understand the phenomena involved. The innovation makes use of resource material developed by the LEPLA Project (LEPLA, 2007).

More importantly, among the respondents to our questionnaire there were a significant number who professed to have no idea about their future use of mathematics (studies: 7.0\%; career: 4.7\%). The effect of this lack of knowledge on their approach to their studies is not clear. Will their ignorance about the role of mathematics in their studies increase their motivation to learn? Or is their understanding of the role of mathematics in their future career of greater significance? It is, perhaps, a function of the emphasis on courses as training for careers rather than for learning in itself. Either way, it seems that many students do not really have any clear understanding of the role of mathematics in their future.

For students from professional disciplines, spelling out how mathematics fits into their degree courses may assist with their learning. Macbean (2004, p. 561) recommends that:

"the more students believe the mathematics is integrated and integral to their degree course the more motivated they are likely to be, and the more meaning oriented their approaches to studying it will become. Consequently, the more a department promotes mathematics as important for the students' degree course and adapts the teaching of it appropriately, the more meaning oriented the students' approach to studying it will be, and the more likely it is for them to develop cohesive conceptions of mathematics."

She notes that this is particularly important for students studying mathematics as a service subject, since context and perceived relevance will greatly affect their motivation, and hence their learning. Evidence from our students supports this: 
Eddie (3rd Year) I'd like to be able to relate it to something that's a real life problem, that's one thing that I find with maths, if I can't relate it to a real life situation, then I don't see a point.

For those who are specialising in mathematics, Houston (1997) advocates introducing students to the "way of life" of a working mathematician. Most mathematicians working outside academia are applied mathematicians who create or modify and then use mathematical models to solve real work problems and to develop understanding of observed phenomena. Hence, he suggests that courses be developed in which students study mathematical models, engage in mathematical modelling and learn the essential mathematical methods and foundations. Such courses will of necessity include the learning of transferable skills such as reasoning, reading, writing and presenting their work in various other media. This approach could also be used for those doing mathematics as a service subject.

Many institutions use an integration of study and employment to develop an awareness of working as a professional, but this is rarely used for potential mathematicians. One strategy, used successfully by the University of Ulster, is to introduce a sandwich placement year into the course, usually as the penultimate year. A student finds an employer for the year, generally with help from the institution. Students thus gain valuable employment experience as they work as mathematicians in one guise or another. In this way they could come to see the purpose and value of their studies.

The same principles apply to integrating mathematics into the vision of their careers for those students who will enter other disciplines. The perception of strong links between the subject at hand and future work may go a long way towards promoting motivation to learn.

Brad (2nd Year) I think everyone has an idea of where they want to end up once they are out of uni and it tends to make you, if you can see the relevance of a subject or of a topic, then you tend to put more work into it and understand it more than something that you can see absolutely no connection with what you want to do.... It's basically things that I can actually use in the workplace that will be important to me.

\section{CONCLUSION}

Although this study focuses on students' views of the role of mathematics, it has wider implications for all students because of the international spread of participants. Overall, our sample had relatively simplistic ideas about their futures, both in terms of the course they were doing and their future work situations, and it is quite possible that a similar result could be found for students in other subjects.

One unexpected result - for which we do not yet have an explanation - was the greater uncertainty about the role of mathematics in their studies (7.0\%), as against their careers $(4.7 \%)$. It is possible that this result reflects the number of students taking targeted degrees, such as engineering, where they may just accept without much thought that the course designers have selected appropriate compulsory subjects. Further investigation of the results, particularly separating out the various subgroups of students in different degrees, could help to illuminate reasons for this difference.

Another point of concern is the relatively low number of students who saw the application of conceptual skills as an important way in which mathematics could affect 
their future studies $(6.9 \%)$ and career (5.8\%). This may suggest that the view of mathematics presented by their teachers is an overly narrow one, a view that could hold students back considerably both in completing their courses and in their subsequent professional lives. On the other hand, a much larger proportion of students expressed views that we have classified as professional - around one-third in each case $(32.5 \%$ for future studies and $36.0 \%$ for future career). Admittedly, some of these were relatively plain statements that "maths will play a major role in my studies/career", but they do represent an awareness of the mathematical aspects of their future.

Too great a number of students seemed to have only a very vague notion of what role mathematics would play in their future. Could this be a reflection of the fact that some of their teachers are unaware of what their students are going to do with their mathematics? The modelling of professional work should be considered as an important aspect of the role of a university lecturer. Approaches such as problem-based learning are not so common in mathematics, though they are occasionally used in statistics (Van Buuren, 2006), yet they seem to lead to consistently clearer and more realistic expectations of a professional role (Abrandt Dahlgren et al., 2006). However, it is disappointing that in the present climate where qualifications for a career are increasingly important, too many students who study mathematics appeared to have little idea about their future use of mathematics.

Other participants showed quite different views. Julia's quote from the interviews shows that she is well aware of the role that mathematics will play in her future, and sums up nicely how many of us feel about mathematics:

Julia [Honours] I think it's, it's mind dazzling how much maths accounts for. I mean to the naked eye maths is one, two, three plus four, have to do this subject and let's get out of school, but if you sit there and look a little bit further, you find maths in all sorts of areas and that, I think, is wonderful. It's like you've learnt this, you've got this knowledge that can be applied to so many different areas, that's got to count for something. It's a powerful thing actually, it's the same theory that engineers use, it's the same theory that financial managers and leaders use, it's exquisite.

\section{ACKNOWLEDGEMENTS}

We would like to extend our very warm thanks to all the many students who participated in the two stages of the project. Without their help we could not have extended our own learning. We would also like to thank the participating universities for the opportunity to do this research. Ethics approval has been granted for all the stages by these universities.

\section{REFERENCES}

Abrandt Dahlgren, M., Hult, H., Dahlgren, L.O., Hård af Segerstad, H. \& Johansson, K. (2006). From senior student to novice worker: learning trajectories in political science, psychology and mechanical engineering. Studies in Higher Education, 31, 5, 569-586

Crawford, K., Gordon, S., Nicholas, J. \& Prosser, M. (1994). Conceptions of mathematics and how it is learned: the perspectives of students entering university. Learning and Instruction, 4, 331-345.

Crawford, K., Gordon, S., Nicholas, J. \& Prosser, M. (1998). University students' conceptions of mathematics. Studies in Higher Education, 23(1), 87-94. 
Crebert, G., Bates, M., Bell, B., Patrick, C-J. \& Cragnolini, V. (2004). Ivory tower to concrete jungle revisited. Journal of Education and Work, 17(1), 47-70.

Dahlgren, L.O., Handal, G., Szkudlarek, T. \& Bayer, M. (2007). Students as Journeymen between cultures of higher education and work. A comparative European project on the transition from higher education to worklife. Higher Education in Europe, 32(4), 305-316.

Dick, T. \& Rallis, S. (1991). Factors and influences on high school students' career choices. Journal for Research in Mathematics Education, 22(4), 281-292.

EDGGS [Embedding the Development and Grading of Generic Skills in the Business Curriculum] (2010). Available from http://www.graduateskills.edu.au/, accessed $21 / 6 / 2010$.

Grigutsch, S. \& Törner, G. (1998). World views of mathematics held by university teachers of mathematics science. Schriftenreihe des Fachbereichs Matematik, preprint 420. Duisburg, Germany: Gerhard Mercator University.

Houston, K. (1997). M's and R's in post-16 mathematics. Teaching Mathematics and Its Application, 16, 192-195.

Houston, K. \& McCartney, M. (2007). An experimental approach to teaching modelling. In C. Haines, P. Galbraith, W. Blum \& S. Khan (Eds.), Mathematical modelling (ICTMA 12): Education, engineering and economics (pp. 451-457). Chichester: Horwood Publishing.

Husman, J. \& Lens, W. (1999). The role of the future in student motivation. Educational Psychologist, 34(2), 113-125.

Keady, G., Fitz-Gerald, G., Gamble, G. \& Sangwin, C. (2006). Computer-aided assessment in mathematical sciences. In Symposium Proceedings, Assessment in Science Teaching and Learning (pp. 69-73). Sydney NSW: UniServe Science.

Kent, P. \& Noss, R. (2003). Mathematics in the university education of engineers. Ove Arup Foundation Report, Ove Arup Foundation, London.

Knight, P. \& Yorke, M. (2003). Employability and good learning in higher education. Teaching in Higher Education, 8(1), 3-16.

LEPLA [Learning Environment for Physics Laboratory Activities] (2007). Available from http://www.lepla.edu.pl, accessed 21/6/2010.

Loughland, T., Reid, A., \& Petocz, P. (2002). Young people's conceptions of environment: a phenomenographic analysis. Environmental Education Research, 8 (2), 187-197.

Macbean, J. (2004). Students' conceptions of, and approaches to, studying mathematics as a service subject at undergraduate level. International Journal of Mathematical Education in Science and Technology, 35(4), 553-564.

Marton, F. \& Booth, S. (1997). Learning and awareness. Mahwah, NJ: Lawrence Erlbaum.

Petocz, P. \& Reid, A. (2006). The contribution of mathematics to graduates' professional working life. In Jeffery, P.L. (Ed.), Australian Association for Research in Education 2005 Conference Papers. Melbourne: AARE. Available from http://www/aare.edu.au/05pap/pet05141.pdf, accessed 21/6/2010.

Petocz, P., Reid, A., Wood, L.N., Smith, G.H., Mather, G., Harding, A., Engelbrecht, J., Houston, K., Hillel, J. \& Perrett, G. (2007). Undergraduate students' conceptions of 
mathematics: an international study. International Journal of Science and Mathematics Education, 5(3), 439-459.

Prosser, M. \& Trigwell, K. (1999). Understanding learning and teaching: The experience in higher education. UK: Society for Research into Higher Education.

Reid, A., Petocz, P, Smith, G.H., Wood, L.N. \& Dortins, E. (2003). Mathematics students' conceptions of mathematics. New Zealand Journal of Mathematics, 32 (Supplement), 163-172.

Reid, A., Wood, L.N., Smith, G.H. \& Petocz, P. (2005). Intention, approach and outcome: university mathematics students' conceptions of learning mathematics. International Journal of Science and Mathematics Education, 3(4), 567-586.

Rochester, S., Kilstoff, K. \& Scott, G. (2005). Learning from success: improving undergraduate education through understanding the capabilities of successful nurse graduates. Nurse Education Today, 25(3), 181-188.

Scott, G. \& Yates, K.W. (2002). Using successful graduates to improve the quality of undergraduate engineering programs. European Journal of Engineering Education, 27(4), 363-378.

Selden, A. (2005). New developments and trends in tertiary mathematics education: or, more of the same? International Journal of Mathematical Education in Science and Technology, 36(2-3), 131-147.

Swan, M. (2006). Designing and using research instruments to describe the beliefs and practices of mathematics teachers. Research in Education, 75, 58-70.

Van Buuren, H. (2006). Teaching statistics and research methods: an integrated approach. In A. Rossman \& B. Chance (Eds.), Proceedings of the Seventh International Conference on Teaching Statistics, ICOTS7, Salvador, Brazil, International Association for Statistics Education.

Weber, R.P. (1990). Basic Content Analysis. Newbury Park, CA: Sage

Wood, L.N. (2004). University mathematics teaching and learning. In B. Perry, G. Anthony \& C. Diezman, (Eds.), MERGA Review of Research in Australia 2000-2003 (pp. 219-242). Flaxton: Post Pressed.

Wood, L.N. \& Kaczynski, D. (2005). University students in USA and Australia: anticipation and reflection on the transition to work. In P. Hager \& G. Hawke, (Eds.), Proceedings of the RWL4: 4th International Conference on Researching Work and Learning, Sydney, Australia (pp. 1-8). Sydney: University of Technology, Sydney.

Wood, L.N., Mather, G., Logan, P. \& Kirkup, L. (2003). Teaching mathematics and physics to engineers: Reflections from the back row. EMAC 2003: Proceedings of the Sixth Engineering Mathematics and Applications Conference, University of Technology, Sydney, 9-11 July 2003 (pp. 295-300). Sydney: Engineering Mathematics Group.

Wood L. \& Reid, A. (2006). Conversations with graduates: reflections on learning mathematics. In Proceedings of the 3rd International Conference on the Teaching of Mathematics at the Undergraduate Level. Istanbul, Turkey: Turkish Mathematical Society. [CD].

\section{CONTACT}

Leigh N. Wood

Faculty of Business and Economics, Macquarie University, NSW 2109, Australia 
Phone: 6129850 4756; Fax: 6129850 6140; Email: leigh.wood@mq.edu.au 